\title{
Factors influencing seasonal and monthly changes in the group size of chital or axis deer in southern India
}

\author{
T R SHANKAR RAMAN* \\ Centre for Ecological Research and Conservation, 3076/5 IV Cross, Gokulam Park, \\ V V Mohalla, Mysore 570002, India \\ *Present address: Centre for Ecological Sciences, Indian Institute of Science, Bangalore \\ 560012, India
}

MS received 4 September 1996; revised 27 January 1997

\begin{abstract}
Chital or axis deer (Axis axis) form fluid groups that change in size temporally and in relation to habitat. Predictions of hypotheses relating animal density, rainfall, habitat structure, and breeding seasonality, to changes in chital group size were assessed simultaneously using multiple regression models of monthly data collected over a 2 yr period in Guindy National Park, in southern India. Over 2,700 detections of chital groups were made during four seasons in three habitats (forest, scrubland and grassland). In scrubland and grassland, chital group size was positively related to animal density, which increased with rainfall. This suggests that in these habitats, chital density increases in relation to food availability, and group sizes increase due to higher encounter rate and fusion of groups. The density of chital in forest was inversely related to rainfall, but positively to the number of fruiting tree species and availability of fallen litter, their forage in this habitat. There was little change in mean group size in the forest, although chital density more than doubled during the dry season and summer. Dispersion of food items or the closed nature of the forest may preclude formation of larger groups. At low densities, group sizes in all three habitats were similar. Group sizes increased with chital density in scrubland and grassland, but more rapidly in the latter-leading to a positive relationship between openness and mean group size at higher densities. It is not clear, however, that this relationship is solely because of the influence of habitat structure. The rutting index (monthly percentage of adult males in hard antler) was positively related to mean group size in forest and scrubland, probably reflecting the increase in group size due to solitary males joining with females during the rut. The fission-fusion system of group formation in chital is thus interactively influenced by several factors. Aspects that need further study, such as interannual variability, are highlighted.
\end{abstract}

Keywords. Grouping behaviour; Axis axis; population density; rainfall; tropical dry evergreen forest; scrubland; grassland; seasonality.

\section{Introduction}

Many species of mammals form social groups during foraging, migration, and other daily activities. The size of groups is often considered a fundamental attribute of the social organization of such species (Jarman 1974; Wilson 1975; Clutton-Brock and Harvey 1978; Clutton-Brock et al 1980; Wittenberger 1980; Rodman 1988), and is described using measures such as the mean group size, and Jarman's (1974) typical group size. Usually, the observed group size is explained as arising from a balance between various advantages of group-living (such as better foraging efficiency, safety from predators, or thermoregulation), and costs (such as competition for food, and susceptibility to parasites or diseases; reviewed by Pulliam and Caraco 1984; Giraldeau

*Fax, 9180 3311280; Email, shankar@ces.iisc.ernet.in. 
1988). In contrast to individuals of species that spend most of their life solitarily and form ephemeral pairs solely for mating, individuals in group-living species are faced with the choice of living in groups of various sizes versus fending for themselves alone. This is particularly so in species that form fluid groups that change in size temporally, in what is also called the fission-fusion system of group formation (Barrette 1991).

The chital or axis deer (Axis axis Erxleben), an endemic cervid of the Indian subcontinent, is known to exhibit a fission-fusion system of fluid group formation and dissolution (Schaller 1967; Fuchs 1977; Mishra 1982; Barrette 1991). The average size of chital groups changes over diurnal (Miura 1981), monthly, and seasonal time periods (Schaller 1967; Sharatchandra and Gadgil 1975; Mishra 1982; Khan et al 1995), as well as in relation to habitat (Barrette 1991; Karanth and Sunquist 1992). Based on these studies, different hypotheses have been put forward to explain the patterns of grouping behaviour in chital (see below). A simultaneous test of the competing hypotheses has not, however, been made. In this paper, predictions of these hypotheses are tested using monthly group size data from a free-ranging population of chital collected over two years from three different habitats: dense forest semi-open scrubland, and open grassland. Multiple regression models have been utilized to examine the effects of various environmental parameters on group size. The results indicate that animal density, food availability and dispersion, habitat structure, and rutting (breeding) activities interactively influence monthly and seasonal changes in chital group size.

\subsection{Hypotheses and predictions}

1.1a Animal density: The influence of animal density within a habitat on group size has not been proposed earlier for chital. Caughley (1977) suggested, however, that in fission-fusion group formation, given that groups have a certain probability of joining in relation to their rate of encounter, a positive relation between group size and animal density is expected.

1.1b Food availability and dispersion: Group sizes increase directly in relation to food availability (Graf and Nichols 1966; Schaller 1967; Sharatchandra and Gadgil 1975; Fuchs 1977; Mishra 1982; Johnsingh 1983; Khan et al 1995). For a given quantity of available food, the more clumped the distribution of the food, the larger is the expected group size. Conversely, if food is evenly dispersed and locally sparse, groups should break up into smaller foraging units to reduce interference competition (Jarman 1974; Sharatchandra and Gadgil 1975; Mishra 1982). These hypotheses ignore the possible confounding effect of food availability on animal density, which can influence group size as postulated above. Seasonal densities and habitat utilization by chital in the study area were found to be closely related to seasonal changes in availability of different foods, which were in turn related to rainfall (Raman et al 1996; see below). Thus, the effect of food availability on group size needs to be examined after removing the effects of animal density on group size, if any.

1.1c Social behaviour and fawning: Larger groups of chital have been noted to form in months when rutting occurs, presumably facilitating social interactions and breeding opportunities (Graf and Nichols 1966; Fuchs 1977). Alternatively, larger groups 
may form during the fawning season, because of the benefits in terms of better predator avoidance conferred by larger groups (Hamilton 1971; Mishra 1982). These lead to the predictions that group size will be directly related to the monthly percentage of rutting stags and fawns, respectively.

1.1d Habitat structure: After removing the effects of factors such as seasonal changes, the more open a habitat is, the larger the group size it should have (Barrette 1991). This is a purely structuralist explanation, claiming that open habitats permit, while closed habitats hinder, the formation of larger groups (Barrette 1991). Here I examine a prediction of this hypothesis, i.e., when other factors such as animal density are controlled, the monthly group size should be highest in open grassland, followed by semi-open scrubland, and least in closed forest.

Besides these hypotheses, predation has been proposed as a factor influencing grouping behaviour in chital (Sharatchandra and Gadgil 1975; Mishra 1982; Khan et al 1995). This has been ignored during this study as the study area did not have any natural predators, except for a few feral dogs (Raman et al 1996). It is reasonable to assume that the level of predation played a minor role, if at all, and did not vary substantially during the study to influence grouping behaviour of chital significantly.

\section{Materials and methods}

\subsection{Study area, vegetation, and climate}

Guindy National Park (GNP) is a $2.7 \mathrm{~km}^{2}$ park in Madras city $\left(13^{\circ} \mathrm{N}, 80^{\circ} \mathrm{E}\right)$. Chital were introduced in the park and occur at high densities of about $212 / \mathrm{km}^{2}$ (estimated using line transects during 1991-92; Raman et al 1996). The natural vegetation of the park is tropical dry evergreen forest (Champion and Seth 1968), classified floristically as the Albizia amara Boiv. community (Puri et al 1989). Three broad habitats occur in the park: (i) Forest (occupying about 92 ha)-characterized by a closed canopy with trees such as Acacia planifrons, Cassia spp., Ficus benghalensis, Feronia elephantum, and Atalantia monophylla. The understory (1 5-2 m tall) is dense, with profuse growth of shrubs such as Glycosmis pentaphylla and Clausena dentata, but grass growth is scarce, (ii) Scrubland (occupying about 160 ha) - this semi-open habitat is characterized by scattered palmyrah palms (Borassus flabellifer) and few other trees. Shrubs such as Carissa spinarum and Randia spp. and over 40 species of grasses, sedges, and herbs occur, (iii) Grassland - this is an open meadow (called Polo Field) about 3.7 ha in area, where at least 67 species of grasses, sedges, and herbs are known to occur.

The mean annual rainfall is $1215 \mathrm{~mm}$ (based on Climatological Table of the Meteorological Dept., for Madras-Minambakkam, 1931-60). Most of the precipitation occurs during the southwest (June-September) and northeast (October-December) monsoons (figure 1). Further details about GNP are available elsewhere (Raman et al 1996). Four seasons were identified using a climatological table and data on rainfall collected on a daily basis for Madras (Minambakkam) during 1991-2 (figure 1): dry season (Jan-Mar), summer (Apr-May 1991 and Apr-Jun 1992), southwest monsoon (June-Sep 1991 and July-Sep 1992), and northeast monson (Oct-Dec). 


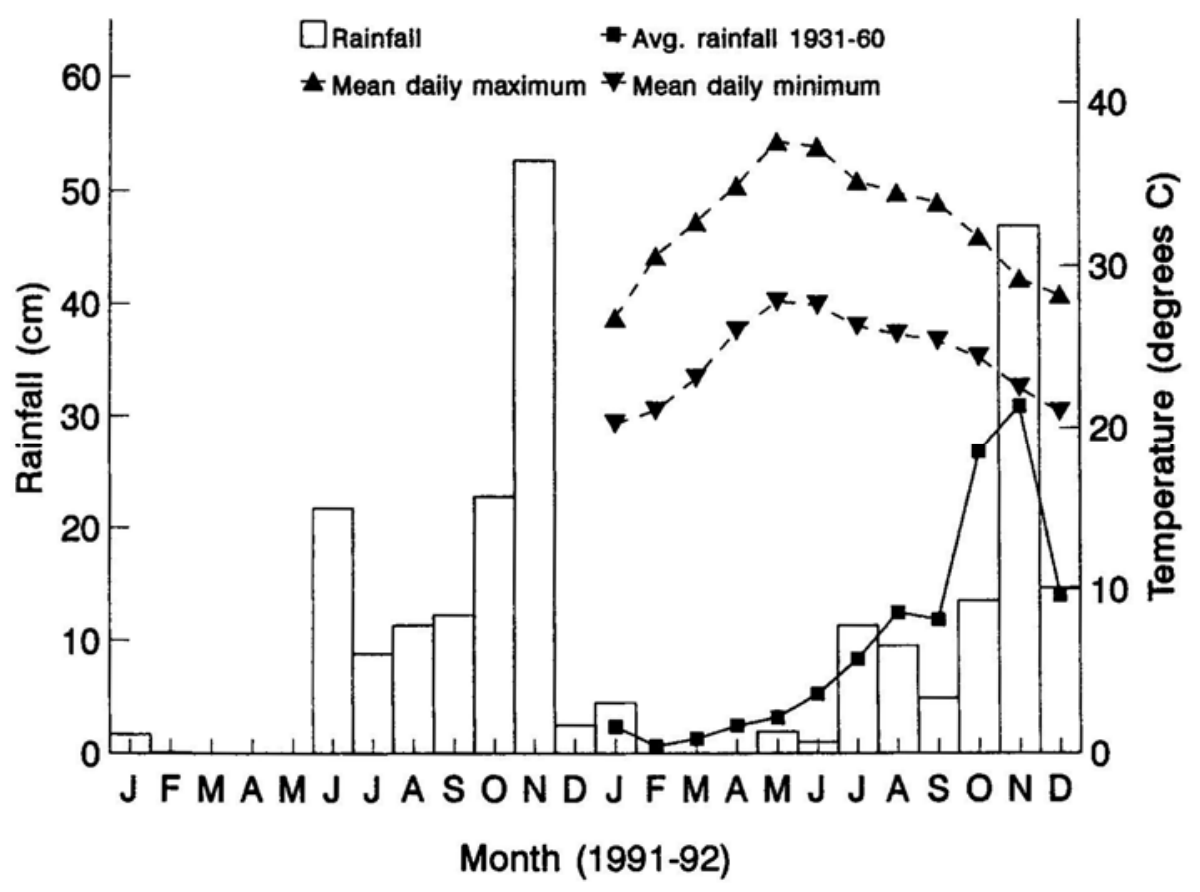

Figure 1. Rainfall and temperature data for the study area (1991-92). Average rainfall is from the Climatological Table of the Meteorological Dept. for Madras, Minambakkam (1931-60).

\subsection{Field methods}

The number of individuals and age-sex composition of groups of chital were recorded during regular line transect sampling (Raman et al 1996) as well as during walks along paths and animal trails in the park. A group was defined after Miura $(1981,1983)$ as the number of individuals interacting with each other, behaving in a coordinated fashion during foraging or moving, or present in close proximity to each other $(<10 \mathrm{~m}$ apart) when first observed. In cases where one or more individuals occurred near the periphery of another group, the peripheral individuals were included in the group if their distance from the outer animals of the group was less than the group's approximate radius. Over 2,700 detections of chital groups were made over the two years of the study (table 1). Only groups where all the individuals could be clearly seen were tallied for group size. If movement of animals or vegetation indicated that some individuals were hidden or only partly visible in dense vegetation, or if the animals were far away $(>50 \mathrm{~m})$ from the observer when detected in the semi-open vegetation, then the group was not included in the data. Although such doubtful cases occurred occasionally, the majority of detections recorded in the field were unambiguous.

The line transects, paths, and trails were sampled more or less uniformly across months in the mornings $(0600-0900 \mathrm{~h})$ and evenings $(1600-1900 \mathrm{~h})$, the time blocks of day when an average of $90 \%$ of the animals are actively foraging or moving (Miura 1981). About 7-11 field visits were made in a month, enabling observation of groups and tallying of group size on a monthly basis in the three major habitats considered here. Age-sex classification of chital observed (described in Raman et al 1996) was used 
Table 1. Number of chital groups tallied in three habitats in Guindy National Park, 1991-92.

\begin{tabular}{lcccr}
\hline Month & Forest & Scrubland & Grassland & Total \\
\hline 1991 & & & & \\
January & 40 & 71 & 12 & 123 \\
February & 35 & 52 & 9 & 96 \\
March & 43 & 44 & 9 & 96 \\
April & 74 & 48 & 3 & 125 \\
May & 48 & 30 & 4 & 82 \\
June & 33 & 49 & 19 & 101 \\
July & 10 & 38 & 23 & 71 \\
August & 12 & 46 & 20 & 78 \\
September & 27 & 54 & 16 & 97 \\
October & 12 & 50 & 23 & 85 \\
November & 21 & 47 & 31 & 99 \\
December & 29 & 68 & 22 & 119 \\
1992 & & & & \\
January & 38 & 97 & 17 & 152 \\
February & 48 & 77 & 3 & 128 \\
March & 63 & 50 & 6 & 119 \\
April & 73 & 75 & 2 & 150 \\
May & 53 & 79 & 12 & 144 \\
June & 65 & 63 & 9 & 137 \\
July & 24 & 90 & 11 & 125 \\
August & 15 & 85 & 32 & 132 \\
September & 15 & 75 & 42 & 132 \\
October & 16 & 42 & 17 & 75 \\
November & 26 & 90 & 40 & 156 \\
December & 21 & 80 & 26 & 127 \\
\hline Total & 841 & 1500 & 408 & 2749 \\
\hline
\end{tabular}

to estimate the monthly percentage of adult males in hard antler (an index of the breeding/rutting season) and the monthly proportion of fawns to females (an index of the fawning season-Schaller 1967; T R S Raman unpublished results).

Chital occur at high densities in Guindy National Park, considerably higher than most other natural areas (Raman et al 1996). Animal density was estimated using line transects in forest and scrubland and total counts in the grassland. Two $1 \mathrm{~km}$-long transects were marked in the scrubland and a single $1 \mathrm{~km}$-long transect was marked in forest to sample them roughly in proportion to their availability. Each transect was sampled twice a month, once each in the morning and evening (Raman et al 1996). Seasonal densities in scrubland and forest were estimated with the Fourier series model (Burnham et al 1980; Karanth and Sunquist 1992; Varman and Sukumar 1995) using the computer program, TRANSECT (White 1987). Monthly total counts were made in the grassland habitat, and these were pooled by season to estimate seasonal densities.

\subsection{Analyses}

Two measures of group size - the mean group size and Jarman's (1974) typical sizewas estimated by habitat, month (or season), and year. A three-way analysis of variance 
with year, season, and vegetation type as the main factors was used to examine whether mean group sizes differed under the influence of any of the factors or interactions among factors. The mean group size is an observer-centred measurement that gives equal weightage to groups of all sizes, and may not reflect the experience of the average individual chital in the same manner as the typical group size. The typical group size is calculated by squaring the sizes of groups, summing across all groups, and dividing the sum by the total number of individuals observed (Jarman 1974). This gives a measure of the size of the group that the average individual finds itself in, and has been proposed as a more animal-centred index of group size (Barrette 1991).

Monthly sample size was low in scrubland and forest for estimating chital density using TRANSECT. A simple strip transect was therefore used to estimate monthly density in these two habitats - the number of individuals detected on a transect was divided by the total area sampled. The strip width used to calculate the area sampled was derived, for scrubland and forest separately, from regressions through the origin, following the method of Caughley (1977:15-16, and 49-50). The seasonal TRANSECT density estimate ( $D$ - on the y-axis) was regressed on the encounter rate $(N / L-$ on the x-axis), where $N$ is the total number of individuals tallied in $L \mathrm{~km}$ of transect. The relationship was observed to be linear and the slope of the regression line $1 / 2 w$, where $w$ is the effective strip width on one side of the transect. This simplified strip transect approach is a useful measure for tracking relative changes in animal abundance from month to month. The effective strip width estimate reduces (if not removes) visibility bias for comparisons across habitats within each month. The effective strip width, $w$, was $37 \mathrm{~m}$ in the scrubland and $17 \mathrm{~m}$ in the forest. It must be noted, however, that the small sample size in some months may have led to imprecise strip transect density estimates. Comparing these with seasonal densities estimated with TRANSECT showed, however, that the monthly estimates were generally accurate enough to fall within the expected range (seasonal 95\% confidence intervals).

Food availability is difficult to estimate for chital which are known to feed on parts of over 160 different plant species (Schaller 1967; Johnsingh and Sankar 1991). They consume predominantly grass in the wet season and browse during the dry season (Schaller 1967; Mishra 1982; Prasad and Sharatchandra 1984). As determining monthly feeding habits of chital in each habitat and measuring availability of each item of their diet was not possible during this study, an alternative index of productivity of food, namely rainfall, was used. Rainfall is known to be related to grassland and scrubland productivity in semi-arid and drier habitats (Sinclair 1977; Misra and Misra 1984). In the forest habitat in the study area, chital feed mainly on fallen leaves and fruits of trees, as grass and edible shrubs are scarce (Raman et al 1996). Such food was available more during the drier months as tree shed their leaves and fruits prior to rains. Monthly rainfall was, however, found to be significantly negatively correlated with the monthly number of trees fruiting in Guindy National Park $(r=-0 \cdot 61, d f=10$, $P=0.03$; phenology data from Rajasekhar 1992); most trees also shed their leaves during the drier months providing food for chital. Rainfall can thus still be used an (inverse) index of productivity of food for chital in forest.

Stepwise multiple regression using SPSS/PC + software (Norušis 1990) was used to examine the influence of monthly animal density, rainfall, percentage of rutting adult males, and fawning on the mean and typical group size within each habitat. The procedure was repeated using $\log (\mathrm{x}+1)$ transformed rainfall as non-linear relationships may exist in relating rainfall to food availability and group size. 
Table 2. Influence of year, habitat, and season on mean group size in chital — Results of analysis of variance.

\begin{tabular}{lrrrr}
\hline & \multicolumn{5}{c}{ Mean } \\
Source of variation & $d f$ & square & $F$ & $P$ \\
\hline & & & & \\
Main effects & 6 & 1048.3 & 55.6 & $<0.001$ \\
Year & 1 & 258.7 & 13.7 & $<0.001$ \\
Habitat & 2 & 1324.3 & 70.2 & $<0.001$ \\
Season & 3 & 567.0 & 30.1 & $<0.001$ \\
2-way interactions & 11 & 202.4 & 10.7 & $<0.001$ \\
Year $\times$ Habitat & 2 & 48.5 & 2.57 & 0.077 \\
Year $\times$ Season & 3 & 46.5 & 2.47 & 0.061 \\
Habitat $\times$ Season & 6 & 321.4 & 17.0 & 0.000 \\
3-way interactions & 6 & 21.0 & 1.12 & 0.351 \\
Year $\times$ Habitat $\times$ Season & 6 & 21.0 & 1.12 & 0.351 \\
Residual & 2725 & 18.87 & & \\
\hline
\end{tabular}

Table 3. Seasonal variation in mean chital group size in the three habitat types in Guindy National Park, Madras, 1991-92.

\begin{tabular}{lccc}
\hline & \multicolumn{3}{c}{ Mean group size (SE, N) } \\
\cline { 2 - 4 } Year/Season & Forest & Scrubland & Grassland \\
\hline Dry season ‘91 & $2 \cdot 30$ & $2 \cdot 32$ & $2 \cdot 60$ \\
& $(0 \cdot 17,118)$ & $(0 \cdot 19,167)$ & $(0 \cdot 44,30)$ \\
Summer ‘91 & $2 \cdot 57$ & $2 \cdot 73$ & $1 \cdot 57$ \\
& $(0 \cdot 25,122)$ & $(0 \cdot 27,78)$ & $(0 \cdot 46,7)$ \\
SW monsoon '91 & $2 \cdot 82$ & $4 \cdot 73$ & $6 \cdot 35$ \\
& $(0 \cdot 34,82)$ & $(0 \cdot 40,187)$ & $(0 \cdot 96,78)$ \\
NE mousoon'91 & $1 \cdot 71$ & $3 \cdot 72$ & $9 \cdot 99$ \\
& $(0 \cdot 12,62)$ & $(0 \cdot 28,165)$ & $(1 \cdot 37,76)$ \\
Dry season '92 & $2 \cdot 02$ & $1 \cdot 91$ & $2 \cdot 15$ \\
& $(0 \cdot 12,149)$ & $(0 \cdot 10,224)$ & $(0 \cdot 36,26)$ \\
Summer '92 & $2 \cdot 23$ & $1 \cdot 97$ & $2 \cdot 13$ \\
& $(0 \cdot 14,191)$ & $(0 \cdot 10,217)$ & $(0 \cdot 39,23)$ \\
SW monsoon '92 & $2 \cdot 22$ & $3 \cdot 16$ & $4 \cdot 66$ \\
& $(0 \cdot 22,54)$ & $(0 \cdot 19,250)$ & $(0 \cdot 81,85)$ \\
NE monsoon'92 & $2 \cdot 32$ & $4 \cdot 05$ & $7 \cdot 93$ \\
& $(0 \cdot 25,63)$ & $(0 \cdot 30,212)$ & $(1 \cdot 27,83)$ \\
\hline
\end{tabular}

SE, Standard error; N, number of groups tallied for group size.

\section{Results}

The analysis of variance (ANOVA) of group size data indicated significant effects of year, season, and habitat type on mean group size (table 2 ). There was also a significant interaction between habitat type and season $(P<0 \cdot 001$, table 2$)$. Other two-way interactions and the three-way interaction between year, habitat type, and season, were not significant.

Seasonally, mean group size and density of chital varied differently in the forest, scrubland, and grassland (table 3). In the forest, there was little variation in mean group 
Table 4. Seasonal variation in chital density in the three habitat types in Guindy National Park, Madras, 1991-92.

\begin{tabular}{|c|c|c|c|}
\hline \multirow[t]{2}{*}{ Year/Season } & \multicolumn{3}{|c|}{ Mean chital density $/ \mathrm{km}^{2}(\mathrm{SE}, \mathrm{N})$} \\
\hline & Forest & Scrubland & Grassland \\
\hline \multirow[t]{2}{*}{ Dry season "91 } & $264 \cdot 7^{a}$ & $150 \cdot 6^{a}$ & $149 \cdot 4^{a}$ \\
\hline & $(61 \cdot 8,20)$ & $(26 \cdot 8,52)$ & $(24-6,19)$ \\
\hline \multirow[t]{2}{*}{ Summer ‘91 } & $381 \cdot 4^{a}$ & $110 \cdot 2^{a}$ & $40 \cdot 5^{b}$ \\
\hline & $(103 \cdot 3,21)$ & $(30 \cdot 6,24)$ & $(13 \cdot 0,12)$ \\
\hline \multirow[t]{2}{*}{ SW monsoon "91 } & & $283 \cdot 4^{b}$ & $591 \cdot 9^{c}$ \\
\hline & $90 \cdot 4^{b}$ & $(43 \cdot 1,68)$ & $(119-7,25)$ \\
\hline \multirow[t]{2}{*}{ NE monsoon '91 } & & $240 \cdot 9 a b$ & $773 \cdot 0^{c}$ \\
\hline & $(25 \cdot 6,19)$ & $(44 \cdot 5,60)$ & $(118 \cdot 4,18)$ \\
\hline \multirow[t]{2}{*}{ Dry season ${ }^{\circ} 92$} & $369 \cdot 3^{a}$ & $98-7^{n}$ & $81 \cdot 1^{a}$ \\
\hline & $(69-6,33)$ & $(20-2,44)$ & $(23.0,18)$ \\
\hline \multirow[t]{2}{*}{ Summer 92} & $390 \cdot 3^{a}$ & $153 \cdot 9^{m}$ & $58 \cdot 9^{a}$ \\
\hline & $(78 \cdot 1,25)$ & $(24 \cdot 6,56)$ & $(20-0,22)$ \\
\hline \multirow[t]{2}{*}{ SW monsoon ' 92} & & $361 \cdot 4^{b}$ & $499 \cdot 2^{b}$ \\
\hline & $97 \cdot 4^{b}$ & $(62 \cdot 2,72)$ & $(127 \cdot 0,21)$ \\
\hline NE monsoon 92 & $(28 \cdot 1,21)$ & $\begin{array}{c}506 \cdot 3^{b *} \\
(84 \cdot 4,84)\end{array}$ & $\begin{array}{c}889 \cdot 2^{b} \\
(160+8,21)\end{array}$ \\
\hline
\end{tabular}

Values with the same alphabet in a column imply no significant difference $(z$ tests, $P>0.05)$ between them within a given year; $\mathrm{N}$ - In forest and scrubland: number of groups detected on transects for the density estimates, in grassland: number of total counts for grassland density estimates; *differed significantly $(z$ tests, $P<0.05)$ from density during that season the previous year.

size with respect to season (table 3), although the density of chital more than doubled from the wet, monsoon seasons to the dry season and summer (table 4). In the scrubland and grassland, mean group size showed clearly discernible variation according to season-increasing during the southwest and northeast monsoon seasons relative to the dry season and summer. Animal density was also higher during the wet seasons in these two habitats (tables 3-4). Both, mean group size and animal density, were higher in the grassland than the scrubland during the wet seasons.

Monthly changes in mean group size, typical group size, and animal density in the three habitats are illustrated in figure 2. The monthly mean and typical group sizes over the two years were significantly positively correlated to each other in forest, scrubland, and grassland $(r=0.71,0.83,0.92$, respectively, $d f=22, P<0.001)$. The results reinforce the patterns observed above - chital group sizes (mean and typical) and density were higher during the wet season months in scrubland and grassland, whereas, in forest, there was little change in group size although density changed substantially.

Bivariate correlations between chital density, and measures of rainfall and group size are given in table 5. Monthly chital density, and group size and rainfall measures were all significantly positively related to each other in scrubland and grassland. Both density and group size tended to be more strongly (and positively) correlated to log rainfall than rainfall in scrubland and grassland (table 5). Conversely, in the forest, chital density was negatively correlated with rainfall and more strongly with the logarithm of rainfall (table 5). No significant correlation was found between measures of 


\section{- Forest - Sorubland -Grassland}
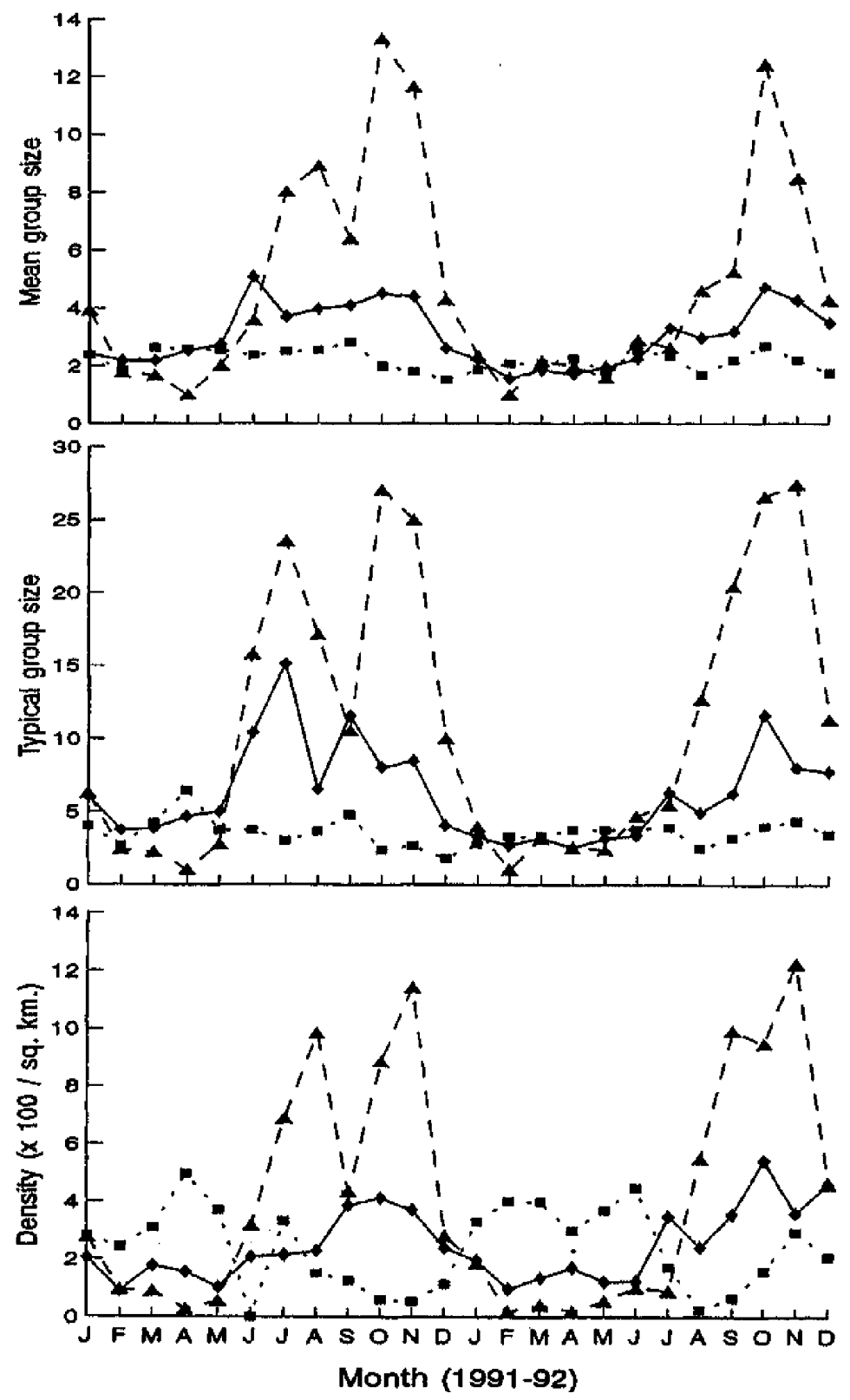

Figure 2. Monthly changes in mean group size, typical group size, and chital density in forest, scrubland, and grassland in Guindy National Park, 1991-92.

chital group size and rainfall in the forest. Forest typical group size was correlated with chital density (table 5).

The monthly changes in chital group size and animal density were also related to the monthly stage of rutting and fawning activities, but not in any consistent or intuitively 
Table 5. Pearson's product-moment correlation coefficients between measures of chital group size, rainfall, and population density in the three habitat types in Guindy National Park, Madras, 1991-1992.

\begin{tabular}{|c|c|c|c|c|}
\hline & $\begin{array}{l}\text { Typical } \\
\text { group size }\end{array}$ & $\begin{array}{l}\text { Animal } \\
\text { density }\end{array}$ & Rainfall & $\begin{array}{l}\log (x+1) \\
\text { rainfall }\end{array}$ \\
\hline & $0-710^{* * *}$ & 0.239 & -0.119 & -0.048 \\
\hline \multirow[t]{3}{*}{ Mean group size } & $0.828 * * *$ & $0.739 * * *$ & $0.736^{* * *}$ & $0-829 * * *$ \\
\hline & $0.922^{* * * *}$ & $0.885^{* * *}$ & $0.690^{* * *}$ & $0.723^{* * *}$ \\
\hline & & $0.453^{*}$ & -0.085 & $-0-158$ \\
\hline \multirow[t]{3}{*}{ Typical group size } & & $0.618^{* * *}$ & $0.495^{*}$ & $0-683^{* * *}$ \\
\hline & & $0.944^{* * *}$ & $0.747^{* * *}$ & $07790^{* * * *}$ \\
\hline & & & $-0.471^{*}$ & $-0 \cdot 644^{* * * *}$ \\
\hline \multirow[t]{2}{*}{ Animal density } & & & $0.581^{* *}$ & $0 \cdot 734^{* * *}$ \\
\hline & & & $0.755^{* * *}$ & $0.765^{* * *}$ \\
\hline
\end{tabular}

Each cell has three correlation coefficients - the uppermost gives the correlations for forest, the middle for scrubland, and the lowermost for grassland. $* P \leq 0 \cdot 05, * * P \leq 0 \cdot 01, * * * P \leq 0 \cdot 001$; $d f=22$ in all cases.

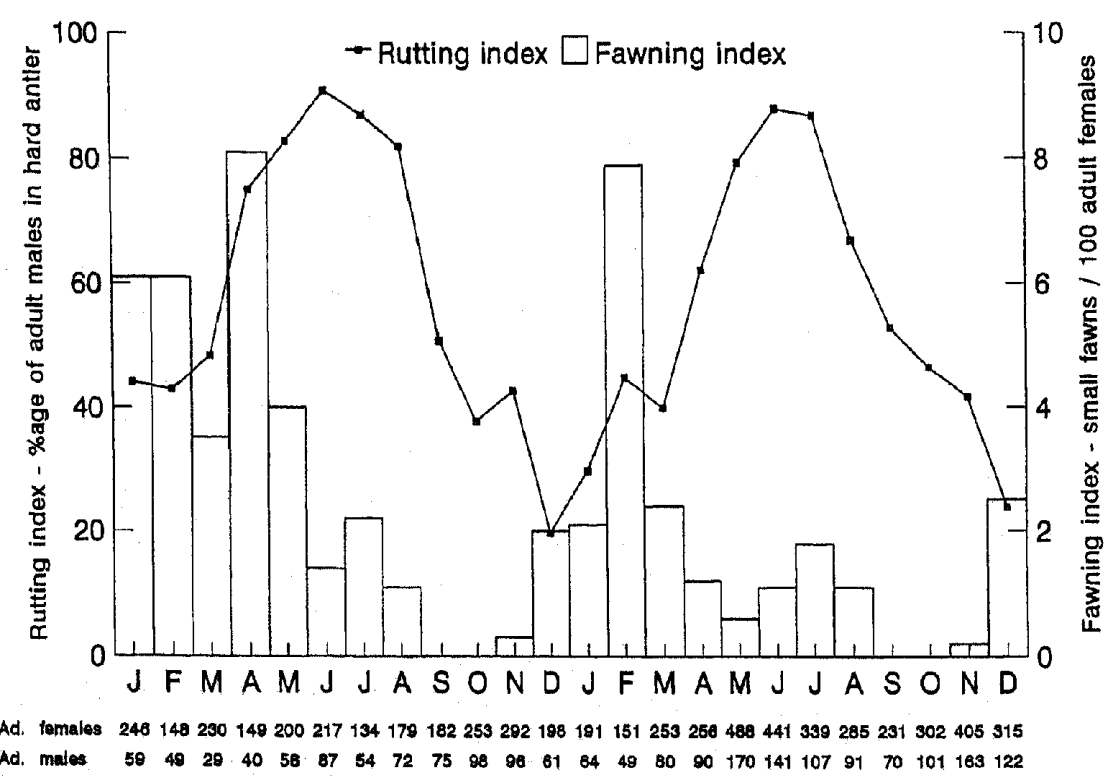

\section{Month (1991-92)}

Figure 3. The rutting and fawning cycles of chital in Guindy National Park (1991-92). Data for Jan-Mar 1991 were unavailable for adult males, and therefore, data for the corresponding months of 1993 were used instead. The number of adult males and females sampled in each month is given in the data table.

obvious manner. The percentage of adult males in hard antler was used as an index of the rut, while the proportion of small fawns to adult females was used an index of fawning. The peak rut of the adult males was in May-June whereas fawning occurred predominantly between December and March (figure 3). In forest, chital mean group size was positively correlated with the rutting index $(r=0 \cdot 50, d f=22, P=0 \cdot 013)$, while 
Table 6. Results of stepwise multiple regression models of chital group size measures in three habitat types. Two classes of models were used-in Class I models, the independent variables were chital density, rainfall, the rutting index, and the fawning index (see text); in Class II models, rainfall is replaced by $\log (x+1)$ rainfall as an independent variable.

\begin{tabular}{|c|c|c|c|c|c|c|}
\hline Habitat & $\begin{array}{l}\text { Dependent } \\
\text { variable }\end{array}$ & $\begin{array}{l}\text { Selected indep- } \\
\text { endent variables }\end{array}$ & $\begin{array}{l}\text { Regression } \\
\text { coefficient (SE) }\end{array}$ & $t$ & $\begin{array}{l}\mathbf{R}^{2} \\
(\%)\end{array}$ & $F$ \\
\hline \multicolumn{7}{|l|}{ Class I models } \\
\hline \multirow[t]{2}{*}{ Forest } & $\begin{array}{l}\text { Mean } \\
\text { group size }\end{array}$ & $\begin{array}{l}\text { Rutting index } \\
\text { (constant) }\end{array}$ & $\begin{array}{l}0.008(0.003) \\
1.747(0.184)\end{array}$ & $\begin{array}{l}2 \cdot 69^{*} \\
9 \cdot 51^{* *}\end{array}$ & 24.8 & $7 \cdot 24^{*}$ \\
\hline & $\begin{array}{l}\text { Typical } \\
\text { group size }\end{array}$ & $\begin{array}{l}\text { Chital density }{ }^{\dagger} \\
\text { (constant) }\end{array}$ & $\begin{array}{l}0.003(0.001) \\
2.834(0.344)\end{array}$ & $\begin{array}{l}2 \cdot 38^{*} \\
8 \cdot 23^{* *}\end{array}$ & 20.5 & $5 \cdot 68^{*}$ \\
\hline \multirow[t]{2}{*}{ Scrubland } & $\begin{array}{l}\text { Mean } \\
\text { group size }\end{array}$ & $\begin{array}{l}\text { Chital density } \\
\text { Rainfall } \\
\text { Rutting index } \\
\text { (constant) }\end{array}$ & $\begin{array}{l}0.005(0.001) \\
0.003(0.001) \\
0.017(0.005) \\
0.593(0.438)\end{array}$ & $\begin{array}{l}4 \cdot 61^{* * *} \\
3 \cdot 46^{* *} \\
3 \cdot 23^{* *} \\
1 \cdot 35\end{array}$ & $54 \cdot 6$ & $26 \cdot 5^{* * *}$ \\
\hline & $\begin{array}{l}\text { Typical } \\
\text { group size }\end{array}$ & $\begin{array}{l}\text { Chital density } \\
\text { Rutting index } \\
\text { (constant) }\end{array}$ & $\begin{array}{r}0.019(0.004) \\
0.060(0.024) \\
-1.957(2.018)\end{array}$ & $\begin{array}{l}4 \cdot 70^{* * *} \\
2 \cdot 49^{*} \\
-0.97\end{array}$ & 38.2 & $13.6^{*}$ \\
\hline \multirow[t]{2}{*}{ Grassland } & $\begin{array}{l}\text { Mean } \\
\text { group size }\end{array}$ & $\begin{array}{l}\text { Chital density } \\
\text { (constant) }\end{array}$ & $\begin{array}{l}0.008(0.001) \\
1.495(0.519)\end{array}$ & $\begin{array}{l}8 \cdot 91^{* * *} \\
2 \cdot 88^{* *}\end{array}$ & $78 \cdot 3$ & $79 \cdot 4^{* * *}$ \\
\hline & $\begin{array}{l}\text { Typical } \\
\text { group size }\end{array}$ & $\begin{array}{l}\text { Chital density } \\
\text { (constant) }\end{array}$ & $\begin{array}{l}0.022(0.002) \\
1.995(0.938)\end{array}$ & $\begin{array}{l}13 \cdot 4^{* * *} \\
21 \cdot 1^{*}\end{array}$ & $89 \cdot 1$ & $179 \cdot 2^{* * *}$ \\
\hline \multicolumn{7}{|c|}{ Class II models } \\
\hline \multirow[t]{2}{*}{ Forest } & $\begin{array}{l}\text { Mean } \\
\text { group size }\end{array}$ & $\begin{array}{l}\text { Rutting index } \\
\text { (constant) }\end{array}$ & $\begin{array}{l}0.008(0.003) \\
1.747(0.184)\end{array}$ & $\begin{array}{l}2 \cdot 69^{*} \\
9 \cdot 51^{* * *}\end{array}$ & 24.8 & $7 \cdot 24^{*}$ \\
\hline & $\begin{array}{l}\text { Typical } \\
\text { group size }\end{array}$ & $\begin{array}{l}\text { Chital density } \\
\text { (constant) }\end{array}$ & $\begin{array}{l}0.003(0.001) \\
2.834(0.344)\end{array}$ & $\begin{array}{l}2 \cdot 38^{*} \\
8 \cdot 23^{* * *}\end{array}$ & $20-5$ & $5 \cdot 68^{*}$ \\
\hline \multirow[t]{2}{*}{ Scrubland } & $\begin{array}{l}\text { Mean } \\
\text { group size }\end{array}$ & $\begin{array}{l}\text { Log rainfall } \\
\text { (constant) }\end{array}$ & $\begin{array}{l}0.880(0-127) \\
1.896(0.210)\end{array}$ & $\begin{array}{l}6.95^{* * * *} \\
9 \cdot 05^{* * *}\end{array}$ & $68 \cdot 7$ & $48 \cdot 3^{* * *}$ \\
\hline & $\begin{array}{l}\text { Typical } \\
\text { group size }\end{array}$ & $\begin{array}{l}\text { Log rainfall } \\
\text { (constant) }\end{array}$ & $\begin{array}{l}2.289(0-522) \\
3.185(0-864)\end{array}$ & $\begin{array}{l}4 \cdot 38^{* * * *} \\
3 \cdot 69^{* * *}\end{array}$ & $46 \cdot 6$ & $19 \cdot 2^{\text {****}}$ \\
\hline \multirow[t]{2}{*}{ Grassland } & $\begin{array}{l}\text { Mean } \\
\text { group size }\end{array}$ & $\begin{array}{l}\text { Chital density } \\
\text { (constant) }\end{array}$ & $\begin{array}{l}0.008(0.001) \\
1.495(0.519)\end{array}$ & $\begin{array}{l}8.91^{* * * *} \\
2 \cdot 88^{* *}\end{array}$ & $78-3$ & $79 \cdot 4^{* * *}$ \\
\hline & $\begin{array}{l}\text { Typical } \\
\text { group size }\end{array}$ & $\begin{array}{l}\text { Chital density } \\
\text { (constant) }\end{array}$ & $\begin{array}{l}0.022(0.002) \\
1.995(0.938)\end{array}$ & $\begin{array}{l}13 \cdot 4^{* * * *} \\
2 \cdot 13^{*}\end{array}$ & $89 \cdot 1$ & $179 \cdot 2^{* * *}$ \\
\hline
\end{tabular}

${ }^{*} P \leq 0 \cdot 05, * * P \leq 0 \cdot 001 ;{ }^{* * *} P \leq 0 \cdot 001 ;{ }^{\dagger}$ density in the corresponding habitat.

density was related to the fawning index $(r=0 \cdot 55, d f=22, P=0 \cdot 005)$. In scrubland and grassland, only the fawning index was (negatively) related with density and both measures of group size $(r<-0 \cdot 51, d f=22, P<0.05$ in all cases except for fawning index vs. typical group size in scrubland where $r=-0 \cdot 36, d f=22, P=0 \cdot 08$ ).

To simultaneously assess the influence of rainfall, animal density, and rutting and fawning indices on chital group size, stepwise multiple regression models were used. Two classes of models were employed, one using rainfall, and the other using log rainfall (table 6). In models involving rainfall, animal density was the main predictor variable of both measures of group size in all habitats (except mean group size in forest) incorporated into the regression models (table 6). Mean group size in forest was, 


\section{- Forest + Scrubland \& Grassland}

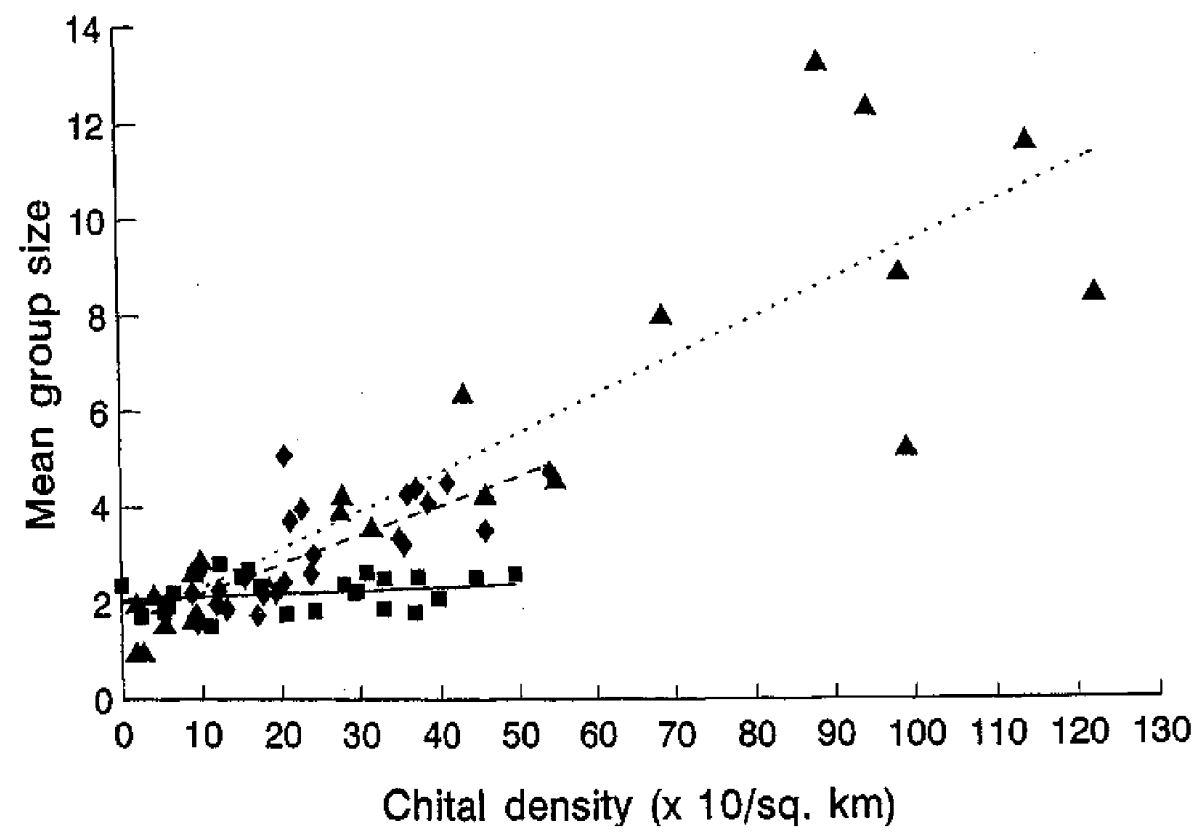

Figure 4. Linear relationships between monthly chital mean group size and density in forest

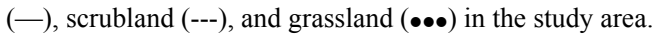

however, related only to the rutting index. The rutting index was also a significant predictor variable of mean and typical group size in the scrubland (table 6). Rainfall had a significant effect only on scrubland mean group size. In models with log rainfall, the same predictor variables as above were significant for the forest and grassland habitats. In scrubland, however, log rainfall was the only significant predictor variable of mean and typical group size (table 6). Notably, the fawning index was not a significant predictor variable in any model.

Since chital density appeared to be the most significant variable influencing group size measures, the role of habitat structure was investigated by plotting mean group size against density. The prediction that grassland had the largest group sizes for a given density, while scrubland had intermediate group sizes and forest had the smallest groups, was examined (figure 4). While the intercepts of the regression lines for the three habitats did not differ significantly, there were differences in the slopes. As noted earlier (table 5), the slopes of the regression lines of mean group size on chital density were significant and positive in grassland and scrubland, whereas it was not significantly different from 0 in the forest $(t=1 \cdot 16, P>0 \cdot 05)$. Also, the slope of the grassland regression line was significantly higher than in scrubland $(F=2.68, P<0.05)$. These results indicate that at low densities mean group sizes are small (around 2-3 individuals) in all three habitats, while at higher densities the group sizes in grassland and scrubland increase, with the increase in grassland being greater than in scrubland. 


\section{Discussion}

The results of the study clearly show that chital density and group size measures show significant seasonal and monthly changes that are closely related to monthly rainfall and type of habitat. Earlier studies have documented differences in seasonal densities of chital in different habitats (Mishra 1982; Karanth and Sunquist 1992; Raman et al 1996), as well as changes in mean group size of chital in relation to season or habitat (Barrette 1991; Karanth and Sunquist 1992; Khan et al 1995). The mechanisms and factors influencing these changes have not, however, been explicitly addressed or considered simultaneously in a single study. The present study has made such an attempt and several noteworthy results emerged.

Although chital density, rainfall, and group size measures were mostly intercorrelated, density appeared to play a predominant role in influencing group size measures as indicated by its selection in most of the stepwise multiple regression models. Chital density increased in relation to rainfall in the grassland and scrubland, but decreased in the forest. The higher availability of fresh grass and browse sprouts in scrubland and grassland is likely to have attracted chital in larger numbers into these habitats, as chital are known to be predominantly grazers during the wet season (Mishra 1982; Prasad and Sharatchandra 1984). The negative relationship between chital density in forest and rainfall is related to the fact that the main forage of chital in this habitat (fallen leaves and fruits of trees) are relatively more abundant during the drier months and summer (Rajasekhar 1992; Raman et al 1996). The movement of chital into grassland and scrubland areas with the rains could also have contributed to the decline in forest density. Chital density was, however, more strongly related to log rainfall than rainfall itself, indicating non-linear changes in density with rainfall. While data are unavailable, it is suggested that this is a result of a non-linear relationship between forage biomass available for chital and rainfall. One can thus assume that chital density and $\log$ rainfall (which were highly correlated) reflect changes in food availability in the different habitats more accurately than does rainfall. This is possibly why log rainfall was the only significant predictor variable for chital group size measures in scrubland, whereas in models with only rainfall, group size was more strongly related to chital density.

The fact that chital density was correlated with rainfall suggests that group size changes may occur in a two-step fashion-first, chital density in a habitat changes in relation to rainfall and food availability, and second, group size increases when density increases because of the higher encounter rate and fusion of groups (as suggested by Caughley 1977). This appears to be the case in the grassland habitat. Conversely, it is possible that groups form or fuse preferentially during high rainfall months (i.e., the probability of groups fusing per encounter increases with rainfall) because a larger number of animals can forage together at a site without interference when food availability per unit area is higher (Wilson 1975; Sharatchandra and Gadgil 1975; Khan et al 1995). Such a mechanism probably regulates changes in chital mean group size in the scrubland, where rainfall had a significant effect on group size, in addition to the effect of increasing animal density. Here individuals can, however, also forage on their own without incurring any cost during high rainfall months when food availability relative to density is higher. Therefore, other advantages to grouping such as social interactions, vigilance and predator detection or avoidance, need to be also invoked to explain changes in group size. 
In the forest habitat, chital grouping patterns were different from scrubland or grassland. The mean and magnitude of change in chital group size measures was lower in forest than in scrubland or grassland. The seasonal mean group size varied between 1.71 (during the 1991 NE monsoon season) to $2 \cdot 82$ (during the 1991 SW monsoon season; see table 3). Smaller group sizes in forest habitats are presumably a consequence of food being more dispersed and scattered throughout the habitat (Jarman 1974; Mishra 1982; Johnsingh 1983; Karanth and Sunquist 1992). Thus, even though chital densities increase substantially in the forest during the dry season, individuals and groups may not coalesce to form larger groups while foraging to avoid competition for forage (Sharatchandra and Gadgil 1975). This should suggest that large groups could form in the forest if food was abundantly available in some patches. During casual observations, large aggregations of chital were in fact noticed forming to feed on locally abundant food sources such as fallen fruits under Ficus benghalensis trees, often in commensal association with bonnet macaques (Krishnan 1972). Thus while chital density in a habitat can be used as an index of overall food availability (as judged by its correlations with rainfall), food dispersion is not accounted for, and may be a critical aspect to measure in future studies.

An alternative suggestion has been that group sizes are smaller in forests as closed habitats hinder, while open habitats facilitate, formation of groups (Barrette 1991; Khan et al 1995). The influence of other factors were not controlled for in the above studies. In the present study, after controlling for the variable that appeared to have the strongest influence on group size (density), group size was found to decrease along the gradient from grassland to scrubland and forest. This result was valid only at higher densities; at low densities groups break up into small sizes (mostly 1-3 individuals, figure 4) in all habitats. These groups typically consist of a female with a fawn and yearling (considered the basic sub-unit of chital social organisation by Graf and Nichols 1966; Schaller 1967), small doe groups, and solitary males (unpublished data). The gradient in group sizes across habitats at higher densities, at first sight, provides support for the structuralist hypothesis of Barrette (1991). Nevertheless, other factors such as food dispersion, differential use of habitats by unisexual fe/male groups that differ in size, and predator avoidance may also be involved.

Social behaviour and phase of the annual reproductive cycle on grouping behaviour, also appeared to have an influence on grouping behaviour of chital. While the fawning index was not a significant predictor variable of group size in any of the multiple regression models, the rutting index was. Fuchs (1977) has remarked on the tendency of chital to form larger groups during the rut in an introduced population in Texas. Rutting males are known to join groups of females to from mixed groups more frequently during the rut (Schalter 1967; Miura 1983; Khan and Vohra 1992). This can explain why mean group size of chital in forest and scrubland was positively correlated to the rutting index during the present study. The lack of significant effect in grassland is likely to be because of two reasons: (i) low sample size of groups during the dry season months, when the rut was in progress, due to low animal density (table 1, figure 2), and (ii) during the wet season months, the effect of solitary males joining female groups (typically larger in size than in the other two habitats) may not have led to a significant change in group size, compared to scrubland and forest, where a single male joining groups of 2-4 females would increase the size of those groups by $33-20 \%$. The mean group size is a more sensitive measure of changes in group size due to the individuals remaining solitary or joining groups (Barrette 1991), and that is probably why typical group size did not show changes in relation to the rutting index. 
Another aspect that emerged during this study is the significant effect of year on mean group size. Inter-annual variability in chital group size in different habitats has not so far been studied in detail. Table 2 shows that the mean group size of chital was smaller in all three habitats during the dry season, summer, and SW monsoon in 1992. In contrast to the positive relationships between chital density and group size within a given year, it is possible that this decrease in chital group size is a result of an increase in chital density between 1991-92. Chital density increased significantly in the study area from $185 \cdot 4 / \mathrm{km}^{2}(\mathrm{SE}=15 \cdot 0)$ during 1991 to $239 \cdot 2 / \mathrm{km}^{2}(\mathrm{SE}=19 \cdot 0)$ during 1992 (Raman et al 1996). The total annual rainfall received decreased, however, from $1313 \mathrm{~mm}$ in 1991 to $1081 \mathrm{~mm}$ in 1992, respectively (figure 1). As chital are already maintained at high densities in Guindy National Park due to artificial feeding and low levels of predation (Raman et al 1996), it is likely that under the increased density in 1992, the food available per individual decreased in the three habitats. In contrast to the proximate positive relationship between density and group size within a given year, increase in density across years (rainfall remaining constant) may lead to groups fragmenting into smaller units to lessen competition over food.

This study's attempt to simultaneously examine the influence of several environmental and social variables on two measures of group size suggests that the fissionfusion system of fluid group formation in chital is strongly influenced by animal density and rainfall. Other factors such as habitat structure and social behaviour too play a role, and our ability to detect their effects may depend on the habitats and index of group size used for comparisons. A caveat that needs to be added is that the chital population in the study area is a high-density population, artificially-fed during some years and thriving in the absence of predation, and is therefore unlike many other natural habitats of chital. Comparable studies from other habitats will be required to assess the generality of these results. It is recommended that future studies also focus on the changes in probability of groups or individuals coalescing as function of animal density and rainfall, on measuring food dispersion, the effects of predator avoidance, and inter-annual variability in relation to per capita food availability, to further elucidate mechanisms driving changes in chital group size.

\section{Acknowledgements}

This research was done while I was a student in the Department of Zoology, Loyola College, Madras. I thank Dr R Sukumar for helpful advice and several othersMr R K G Menon, Mr M D Madhusudan, and Drs N V Joshi and C Barrette-for useful discussions and literature. The Tamil Nadu Forest Dept, kindly gave permission to carry out the research in Guindy National Park. I thank the Centre for Ecological Sciences, Indian Institute of Science for support and facilities.

\section{References}

Barrette C 1991 The size of Axis deer fluid groups in Wilpattu National Park, Sri Lanka; Mammalia 55 207-220

Burnham K P, Anderson D R and Laake J L 1980 Estimation of density from line transect sampling of biological populations; Wildl. Monogr. 72 1-202

Caughley G 1977 Analysis of vertebrate populations (Chichester: John Wiley) 
Champion H G and Seth S K 1968 A revised survey of the forest types of India (Delhi: Manager of Publications, Govt. of India)

Clutton-Brock T H, Albon S D and Harvey P H 1980 Antlers, body size and breeding group size in Cervidae; Nature (London) 285 565-567

Clutton-Brock T H and Harvey P H 1978 Mammals, resources and reproductive strategies; Nature (London) 273 191-195

Fuchs E R 1977 Behavior; in The Axis deer in Texas (ed.) E D Abies (Texas: Caesar Kleberg) pp 24-52

Giraldeau L 1988 The stable group and the determinants of foraging group size; in The ecology of social behaviour (ed.) C N Slobodchikoff (San Diego: Academic Press) pp 33-53

Graf W and Nichols L 1966 The axis deer in Hawaii; J. Bombay Nat. Hist. Soc. 63 629-734

Hamilton W D 1971 Geometry for the selfish herd; J. Theor. Biol. 31 295-311

Jarman P J 1974 The social organisation of antelope in relation to their ecology; Behaviour 48 216-267

Johnsingh A J T 1983 Large mammalian prey-predators in Bandipur; J. Bombay Nat. Hist. Soc. 80 1-57

Johnsingh A J T and Sankar K 1991 Food plants of chital, sambar and cattle on Mundanthurai Plateau, Tamil Nadu, south India; Mammalia 55 57-66

Karanth K U and Sunquist M E 1992 Population stucture, density and biomass of large herbivores in the tropical forests of Nagarahole, India; J. Trop. Ecol. 8 21-35

Khan J A, Chellam R and Johnsingh A J T 1995 Group size and age-sex composition of three major ungulate species in Gir Lion Sanctuary, Gujarat, India; J. Bombay Nat. Hist. Soc. 92 295-302

Khan J A and Vohra U 1992 Group size and group composition of chital (Axis axis) in Gir, Gujarat, India; Mammalia 56 662-665

Krishnan M 1972 An ecological survey of the larger mammals of peninsular India; J. Bombay Nat. Hist. Soc. 69 469-501

Mishra H R 1982 The ecology and behaviour of chital (Axis axis) in the Royal Chitwan National Park, Nepal, $\mathrm{Ph} . \mathrm{D}$, thesis, Univ. of Edinburgh, Edinburgh, UK

Misra M K and Misra B N 1984 Biomass and primary production in an Indian grassland. Trop. Ecol. 25 239-247

Miura S 1981 Social behaviour of the Axis, deer during the dry season in Guindy sanctuary, Madras; $J$. Bombay Nat. Hist. Soc. 78 125-138

Miura S 1983 Grouping behaviour of male sika deer in Nara Park, Japan; J. Mammal. Soc. Jpn. 9 279-284

Norušis M J 1990 SPSS/PC + Statistics 4.0 (Chicago: SPSS Inc.)

Prasad S N and Sharatchandra H C 1984 Primary production and consumption in the deciduous forest ecosystem of Bandipur in south India; Proc. Indian Acad. Sci. (Plant Sci.) 93 83-97

Pulliam H R and Caraco T1984 Living in groups: Is there an optimal group size?; in Behavioural ecology: An evolutionary approach (eds) H R Pulliam and T Caraco (Oxford: Blackwell) pp 122-147

Puri G S, Gupta R K, Meher-Homji V M and Puri S 1989 Forest ecology: Plant form, diversity, communities and succession (New Delhi: Oxford and IBH)

Rajasekhar B 1992 Observations on the vegetation of Guindy National Park; Blackbuck 8(2) 38-42

Raman T R S, Menon R K G and Sukumar R 1996 Ecology and management of chital and blackbuck in Guindy National Park, Madras; J. Bombay Nat. Hist. Soc. 93 178-192

Rodman P S 1988 Resources and group sizes in primates; in The ecology of social behaviour (ed.) C N Slobodchikoff (San Diego: Academic Press) pp 83-108

Schaller G B 1967 The deer and the tiger (Chicago: University of Chicago Press)

Sharatchandra H C and Gadgil M 1975 A year of Bandipur; J. Bombay Nat. Hist. Soc. 72 623-647

Sinclair ARE 1977 The African buffalo (Chicago: University of Chicago Press)

Varman K S and Sukumar R 1995 The line transect method for estimating densities of large mammals in a tropical deciduous forest: An evaluation of models and field experiments; J. Biosci. 20 273-287

White G C1987 Program TRANSECT-Line transect data analysis program, Version 2. 1, Utah Cooperative Wildlife Research Unit

Wilson E O 1975 Sociobiology: The new synthesis (Cambridge: Belknap Press)

Wittenberger J F 1980 Group size and polygamy in social mammals; Am. Nat. 113 197-222 